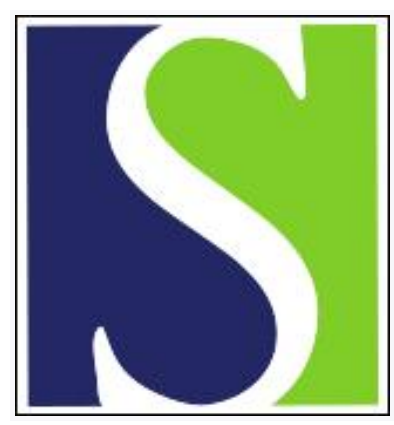

Scand J Work Environ Health 1988;14(1):17-20

https://doi.org/10.5271/sjweh.1956

Issue date: Feb 1988

Disturbed iron metabolism among workers exposed to organic sulfides in a pulp plant.

by Klingberg J, Beviz A, Ohlson CG, Tenhunen R

Affiliation: Lindehalsan Industrial Health Center, Frovi, Sweden.

This article in PubMed: www.ncbi.nlm.nih.gov/pubmed/3353691

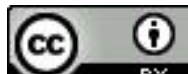




\title{
Disturbed iron metabolism among workers exposed to organic sulfides in a pulp plant
}

\author{
by Jan Klingberg, MD, ${ }^{1}$ André Beviz, MSc, ${ }^{2}$ Carl-Göran Ohlson, $M D,{ }^{2}$ Raimo Tenhunen, $M^{3}$
}

\begin{abstract}
KLINGBERG J, BEVIZ A, OHLSON C-G, TENHUNEN R. Disturbed iron metabolism among workers exposed to organic sulfides in a pulp plant. Scand J Work Environ Health 14 (1988) 17-20. The aim of this study was to investigate a possible relationship between exposure to sulfides and disturbances of the synthesis of heme and the erythrocytes. Eighteen workers exposed to sulfides at a pulp and paper plant were examined and compared with individually matched referents from a thermomechanical pulp plant without such exposure. The exposure levels of methylmercaptan, dimethylsulfide, and dimethyldisulfide were low. However, five subjects were exposed to high levels of short duration, and their data were analyzed separately. The activity of the enzymes delta-aminolevulinic acid synthase and heme synthase in reticulocytes, characteristics of the erythrocytes, and the iron status were analyzed. A minor decrease, not statistically significant, was observed for the enzymes among the five highly exposed subjects. However, the concentrations of iron and transferrin were elevated and the concentration of ferritin was low in comparison to the corresponding levels of the referents. This combination will not occur spontaneously. A previous study indicated that sulfides may inhibit heme synthesis, and the present study suggests that they may also disturb iron metabolism.
\end{abstract}

Key terms: delta-aminolevulinic acid synthase, ferritin, heme synthase, transferrin.

Hydrogen sulfide and organic sulfides impair cellular metabolism by inhibiting cytochrome oxidase in the mitochondria and cause the so-called "histotoxic hypoxia" (2). They do not impair the transport of oxygen by hemoglobin, nor do they cause the formation of sulfhemoglobin. In high concentrations they cause anosmia and respiratory paralysis with consequent asphyxia, and the outcome may be fatal. A report from Finland described cumulative biochemical effects in the heme synthesis among 17 workers in pulp production. Decreased activities of delta-aminolevulinic acid synthase and heme synthase in reticulocytes were observed and considered to be caused by low-level hydrogen sulfide and methylmercaptan exposure (6).

At a pulp and paper plant in the middle part of Sweden a decreased mean corpuscular hemoglobin concentration was found in sulfide-exposed workers. The hypothesis that sulfides can cause measurable disturbances in the synthesis of heme motivated a controlled study of the health status of the exposed workers. The aim of this study was to investigate a possible relationship between exposure to low levels of organic sulfides and hydrogen sulfide and changes in the erythrocytes or inhibition of the activities of deltaaminolevulinic acid synthase and heme synthase.

' Lindehälsan Industrial Health Center, S-701 40 Frövi, Sweden.

2 Department of Occupational Medicine, Medical Center Hospital, S-701 85 Örebro, Sweden.

${ }^{3}$ Department of Clinical Chemistry, University of Helsinki, Meilahti Hospital, SF-00290 Helsinki, Finland.

Reprint requests to: Dr C-G Ohlson, Department of Occupational Medicine, Medical Center Hospital, S-701 85 Orebro, Sweden.

\section{Subjects and methods}

\section{Study groups}

Workers continuously exposed to low concentrations of sulfides at the pulp and paper plant were the source population, and 20 subjects engaged in maintenance of the process were chosen for this study. They were individually matched to referents chosen from workers not exposed to sulfides at a thermoniechanical pulp plant located not far away. The work conditions were consequently very similar at the two plants, except for the exposure to sulfides.

Matching factors were age ( \pm 2 years), smoking habits, and physical activity. However, two dropouts from the reference group reduced the final study population to 18 matched pairs.

The mean age of the exposed subjects was 40.3 years, and that of the referents 41.5 years. Eleven exposed subjects, but only eight referents, had regular physical activity.

\section{Exposure}

The exposure to sulfides was estimated from registered peak levels and measured mean levels. All events leading to the exhaust of sulfides in the plant were registered, eg, exchange of colanders in pumps or uncontrolled disturbances in the process leading to leakage into the worksites. The subjects exposed to such peak levels of sulfides were registered. However, no information could be obtained as to the concentrations of the peak levels. Five exposed subjects experienced such peak levels within a period of two months before the blood samples were drawn. They 
are referred to in the following text as "highly exposed."

The estimations of the mean concentration levels of organic sulfides were based on 24 short-time air samples. These samples were drawn on four occasions when production was normal and during the period when the medical examinations were carried out. The air samples were collected in evacuated gas pipettes of pyrex glass. The pipettes were brought within $1 \mathrm{~h}$ to the laboratory where $2 \mathrm{ml}$ of the air samples was injected directly into a gas chromatograph (Perkin Elmer Sigma-1). The instrument settings were as follows: nitrogen at a flow rate of $20 \mathrm{ml} / \mathrm{min}$, hydrogen/air pressure $20 / 24,65^{\circ} \mathrm{C}$. The column used was of the type SP-2100, 1/8','

Three organic sulfides were analyzed - methylmercaptan, dimethylsulfide, and dimethyldisulfide. The mean concentrations of the sulfides were low, generally below the detection limits of the three sulfides, ie, $<0.2$ ppm for methylmercaptan and $<0.05 \mathrm{ppm}$ for dimethylsulfide and dimethyldisulfide. However, during the exchange of a colander, concentration levels of one or two orders of magnitude higher were registered. Hydrogen sulfide was not measured.

Table 1. Mean differences between pairs of exposed subjects and referents (matched for age, smoking habits, and physical activity) in the activities of heme synthase and delta-aminolevulinic acid synthase in reticulocytes. The normal values, as reflected by the values of the referents, are given for compari son.

\begin{tabular}{|c|c|c|c|c|c|c|}
\hline \multirow{3}{*}{ Enzyme } & \multicolumn{4}{|c|}{ Mean paired differences } & \multirow{2}{*}{\multicolumn{2}{|c|}{$\begin{array}{c}\text { Values of } \\
\text { the } \\
\text { referents } \\
(\mathrm{N}=18)\end{array}$}} \\
\hline & \multicolumn{2}{|c|}{$\begin{array}{l}\text { All exposed } \\
\text { workers } \\
(\mathbf{N}=18)\end{array}$} & \multicolumn{2}{|c|}{$\begin{array}{l}\text { Highly exposed } \\
\text { workers } \\
(N=5)\end{array}$} & & \\
\hline & Mean & SD & Mean & SD & Mean & SD \\
\hline $\begin{array}{l}\text { Heme synthase } \\
\text { (pmol heme/ } \mathrm{h} \times 10^{6} \\
\text { reticulocytes) }\end{array}$ & -1.01 & 8.98 & -2.34 & $5.29^{*}$ & 9.72 & 7.7 \\
\hline $\begin{array}{l}\text { Delta-aminolevulinic } \\
\text { acid synthase } \\
\text { (pmol ALA/h } \times 10^{6} \\
\text { reticulocytes) }\end{array}$ & -0.035 & 0.196 & -0.102 & $0.22 * *$ & 0.181 & 0.13 \\
\hline
\end{tabular}

$* t=-0.99$ (not significant), $* t=-1.04$ (not significant).

Table 2. Mean differences between pairs of exposed subjects and referents (matched for age, smoking habits, and physical activity) in the concentrations of serum iron, transferrin, and ferritin. The normal values, as reflected by the values of the referents, are given for comparison.

\begin{tabular}{|c|c|c|c|c|c|c|}
\hline \multirow{3}{*}{ Parameter } & \multicolumn{4}{|c|}{ Mean paired differences } & \multirow{2}{*}{\multicolumn{2}{|c|}{$\begin{array}{c}\text { Values of } \\
\text { the } \\
\text { referents } \\
(\mathrm{N}=18)\end{array}$}} \\
\hline & \multicolumn{2}{|c|}{$\begin{array}{l}\text { All exposed } \\
\text { workers } \\
(N=18)\end{array}$} & \multicolumn{2}{|c|}{$\begin{array}{l}\text { Highly exposed } \\
\text { workers } \\
(\mathrm{N}=5)\end{array}$} & & \\
\hline & Mean & SD & Mean & SD & Mean & SD \\
\hline $\begin{array}{l}\text { Iron }(\mu \mathrm{mol} / \mathrm{l}) \\
\text { Transferrin }(\mu \mathrm{mol} / \mathrm{l}) \\
\text { Ferritin }(\mu \mathrm{g} / \mathrm{l})\end{array}$ & $\begin{array}{c}-1.9 \\
7.89 \\
-14.8\end{array}$ & $\begin{array}{l}10.2 \\
16.8 \\
126\end{array}$ & $\begin{array}{r}9.4 \\
26.4 \\
-98.6\end{array}$ & $\begin{array}{l}3.1^{*} \\
11.8^{* *} \\
41.5^{* *}\end{array}$ & $\begin{array}{r}23.4 \\
63.8 \\
111\end{array}$ & $\begin{array}{l}7.7 \\
10.6 \\
85\end{array}$ \\
\hline
\end{tabular}

\section{Medical examinations}

All the subjects, except one exposed subject and one referent, completed a questionnaire on general symptoms like fatigue, irritability, headache, and irritation of the skin and mucous membranes. Information was also collected on medical history and eating habits.

Blood samples were drawn at the same time within each matched pair, in the morning before the day shift and with the subjects fasting.

Analyses of reticulocytes for delta-aminolevulinic acid synthase and heme synthase were carried out within $24 \mathrm{~h}$ at the Department of Clinical Chemistry, University of Helsinki. The blood samples were cooled to $5^{\circ} \mathrm{C}$ during the transport. The methods have been described in detail elsewhere (4).

The erythrocytes were studied by means of standard routine hospital methods, and the following parameters were measured: the mean corpuscular volume, the mean corpuscular hemoglobin concentration, and the erythrocyte concentration. In addition, the concentrations of serum hemoglobin, haptoglobin, iron, transferrin, and ferritin were measured. The measurement of haptoglobin, transferrin, and ferritin was carried out by immunologic methods.

\section{Statistical methods}

The intrapair differences were tested with Student's t-test for paired observations. Only two-tailed significance levels were applied.

\section{Results}

The activities of delta-aminolevulinic acid synthase and heme synthase were lower among the exposed subjects than among the referents. These differences were due to low activity levels among the five highly exposed subjects (table 1). The differences were, however, not statistically significant.

The concentrations of serum iron and transferrin were elevated among the highly exposed subjects, and the concentration of ferritin was low in comparison with that of the referents (table 2). These differences were statistically significant $(\mathrm{t}=6.89,5.0$, and -5.3 , respectively; $P<0.01)$. However, only minor and statistically insignificant differences in the concentrations of erythrocytes, hemoglobin, and haptoglobin were observed between the exposed subjects and referents. The prevalence of diffuse symptoms as reported in the questionnaires was similar in the two study groups, and the minor differences observed were not statistically significant.

A short time after this study was completed, a minor explosion occurred which led to a leakage of substantial amounts of sulfides out on the roof of the building. Six subjects who were not participants of the study group and who worked regularly outside the building were engaged in the clean-up. Two days and ten days 
later blood samples were drawn from these persons and analyzed with regard to iron concentration. The mean value $2 \mathrm{~d}$ after the exposure was $28.8 \mu \mathrm{mol} / \mathrm{l}$ (which is close to the upper normal limit of this parameter), and $10 \mathrm{~d}$ after the exposure the mean value had decreased to an approximately normal level of 19.3 $\mu \mathrm{mol} / \mathrm{l}$. This difference was statistically significant $(\mathrm{t}=3.32 ; \mathrm{P}=0.02)$.

\section{Discussion}

A small decrease in the activities of deltaaminolevulinic acid synthase and heme synthase was observed among five subjects exposed to peak levels of sulfides. The differences were not statistically significant even though the deviations were congruent with the observation on the inhibition of heme synthesis by sulfides. The inhibition of delta-aminolevulinic acid synthase and heme synthase, both mitochondrial enzymes, might be a sign of mitochondrial destruction. No changes in the erythrocyte number or morphology were found which would not be likely at the small levels of differences of the enzyme activities.

The marked differences in the concentrations of iron, transferrin, and ferritin were indicative of a disturbance of the iron metabolism but were not predicted from the hypothesis. This combination of high iron concentration and low ferritin concentration will not occur spontaneously or as a result of a known disease. Theoretically, this combination might occur in the very beginning of treatment with iron in states of iron depletion. None of the study subjects had taken iron orally or had been a blood donor during the months prior to the drawing of the blood samples.

The combination of a high concentration of iron and a low concentration of ferritin in blood could, however, be explained by the assumption that the uptake of iron from blood into the cells of the reticuloendothelial system is blocked by sulfides. Iron is transported into the cells bound to transferrin, and this transport is energy dependent and can be blocked by agents reacting with sulfhydryl groups (1). The turnover of iron in blood is high, the amount transported into the immature red cells in $24 \mathrm{~h}$ usually being five to ten times the amount in the blood at a time (3). It may therefore be assumed that iron metabolism is a sensitive indicator of inhibited transport into the cells and that the iron concentration in blood may increase markedly even after a minor inhibition of its uptake.

Ferritin is synthezised in the cells of the reticuloendothelial system proportionally to the magnitude of the iron supply and uptake. The occurrence of ferritin in blood is considered to be a secondary phenomenon, perhaps arising from reticuloendothelial cells (5). The fact that a large portion of its protein is glycosylated favors the concept that ferritin is a secretory protein, perhaps arising in membrane-bound polyribosomes ( 7 ).

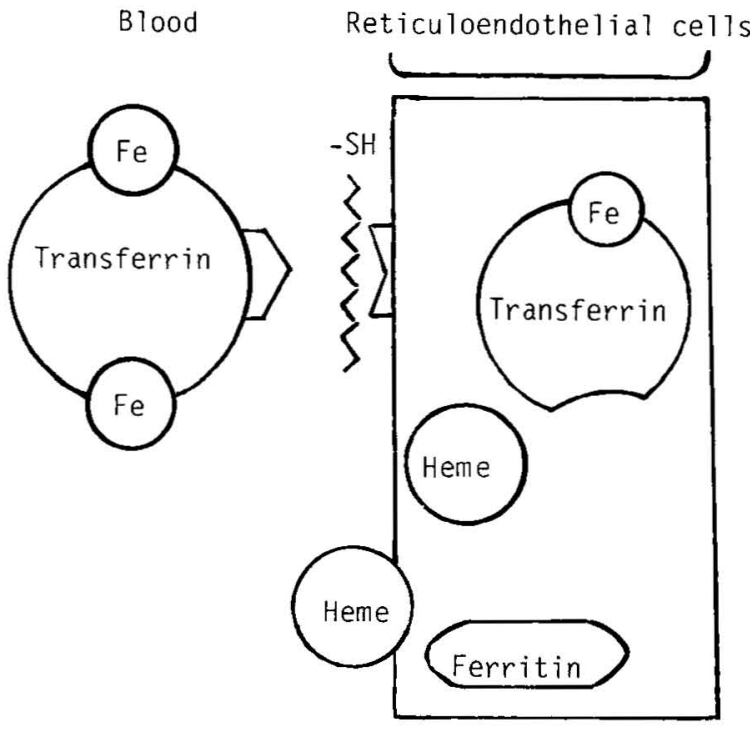

Figure 1. Illustration of the hypothesis that sulfides (ie, -SH containing agents) block the uptake of iron (Fe) transferrin.

The hypothesis of a disturbance of the heme synthesis by sulfides may therefore be extended to include an influence of iron metabolism as well. Most of the iron entering the plasma for distribution by transferrin originates from the cells of the reticuloendothelial system. This iron is derived mainly from hemoglobin catabolism. In sulfide-exposed persons, however, there are no signs of increased hemoglobin degradation. A much smaller fraction of the plasma iron originates from other tissues, particularly from body iron reserves, such as hepatocytes. The low ferritin concentration of plasma also seems to exclude the possibility of an increased iron "leakage" from hepatocytes into the plasma. As depicted in figure 1, sulfides (ie, -SH containing agents) could primarily block the normal uptake of iron transferrin and cause increased iron concentrations in the blood. A minor inhibition may, however, not cause measurable effects in the end product, ie, in the erythrocytes, but nevertheless may decrease the synthesis of ferritin and its occurrence in blood.

This hypothesis was corroborated by the findings from the six subjects who were exposed to sulfides during the clean-up on the roof of the building. The change in their mean iron concentration was consistent with the hypothesis even though the mean values at both times were within normal limits.

The measured concentrations of organic sulfides in the air of the plant were very low and the observed exposure-effect relationships were based only on the occurrence of peak exposures. The time relationships were not clear in this study. It may take a long time to restore the synthesis of heme after inhibition by acute exposure to sulfides. According to Finnish experience the synthesis of heme may be restored only 
after about one month, and it is more probable that the synthesis of enzymes is inhibited, not the activities of enzymes per se (Tenhunen, personal communication). The finding of increased iron concentrations $2 \mathrm{~d}$ after the accidental exposure and their restoration to normal after $10 \mathrm{~d}$ indicates that the inhibition of the iron transport is of shorter duration than the inhibition of the synthesis of heme after acute exposure to sulfides.

In conclusion, this study of 18 workers at a pulp and paper plant indicates that exposure to low levels of organic sulfides may inhibit the intracellular uptake of iron in the reticuloendothelial system. However, the decrease of the synthesis of heme reported in previous studies was not statistically significant in this study, probably because of the low exposure levels.

\section{Acknowledgments}

We thank Mr L Jansson for analyzing the air samples, Ms A-M Porat for collecting the medical data, and Ms $\mathrm{U}$ Dyfverman and $\mathrm{Mr} \mathrm{H}$ Karlsson for their assistance.
We are grateful to Ms C Söderqvist for typing the manuscript. We also thank the participating workers and the staff of Frövifors Bruk for their cooperation.

\section{References}

1. Aisen $P$, Brown EB. The iron-binding function of transferrin in iron metabolism. Semin Hematol 14 (1977) $31-53$.

2. Beauchamp RO, Bus JS, Popp JA, Boreiko CJ, Andjelkovich DA. A critical review of literature on hydrogen sulfide toxicity. CRC Crit Rev Toxicol 13 (1984) 25-97.

3. Cavill I, Ricketts C, Napier JAF, Jacobs A. Ferrokinetics and erythropoiesis in man: Red-cell production and destruction in normal and anaemic subjects. $\mathrm{Br} \mathbf{J}$ Haematol 35 (1977) 33-40.

4. Pasanen AVD, Salmi M, Vuopio P, Tenhunen R. Heme biosynthesis in sideroblastic anemia. Int J Biochem 12 (1980) 969-974.

5. Simes MA, Dallman PR. New kinetic role for serum ferritin in iron metabolism. Br J Haematol 28 (1974) 7-18.

6. Tenhunen R, Savolainen H, Jäppinen P. Changes in haem synthesis associated with occupational exposure to organic and inorganic sulphides. Clin Sci 64 (1983) 187-191.

7. Worwood M. Serum ferritin. CRC Crit Rev Clin Lab Sci 10 (1979) 171.

Received for publication: 28 August 1987 